\title{
Editorial
}

\section{Introduction to the Special Issue of Onward! Essays 2018}

\section{Onward! Essays}

\section{Richard P. Gabriel ${ }^{\mathrm{a}}$}

a Hasso Plattner Institute, University of Potsdam, Germany

Abstract In 2018, Onward! accepted three essays. Their authors were given the choice of publication in the ACM Onward! 2018 proceedings or in The Art, Science, and Engineering of Programming. One essay is published in full here, as are the extended abstracts of the two others.

Keywords abstraction, programming language design, software engineering

The Art, Science, and Engineering of Programming 


\section{Introduction to the Special Issue of Onward! Essays 2018}

An Onward! Essay is a clear and compelling pieces of writing about a topic important to the software community; it can be an exploration of the topic and its impact, or a story about the circumstances of its creation; it can present a personal view of what is, explore a terrain, or lead the reader in an act of discovery; it can be a philosophical digression or a deep analysis. It can describe a personal journey, perhaps the one the author took to reach an understanding of the topic. The subject area-software, programming, and programming languages-is interpreted broadly and can include the relationship of software to human endeavors, or its philosophical, sociological, psychological, historical, or anthropological underpinnings.

In 2018, Onward! Essays invited not only experienced academics but graduate students to submit essays with constructive criticism of current software development technology and practices, as well as presentations of ideas that could change the realm of software development. Practitioners dissatisfied-or satisfied!-with the state of our art were also encouraged to share insights about how to reform-or improvesoftware development, perhaps by presenting detailed examples of a new approach, demonstrating concrete benefits and potential risks.

Onward! Essays was not looking for research-as-usual papers-an essay doesn't require definitive validation; however, regardless of its form or topic, the essay must have "substance." An essay may or may not have a conclusion, but it must provide some insight or compelling argument, either directly or indirectly stated; the reader should be left-perhaps after some reflection-in no doubt about the claimed insight or argument. The key characteristic of a successful essay is that it shows a keen mind coming to grips with a tough or intriguing problem in such a way that, as Virginia Woolf wrote, "it explains much and tells much." [5]

The program committee was as follows:

Craig Anslow Victoria University of Wellington, New Zealand

Elisa Baniassad University of British Columbia, Canada

Siobhán Clarke Trinity College Dublin, Ireland

Richard P. Gabriel Hasso Plattner Institute (Chair), California

Charlotte Herzeel imec, Belgium

Graham Hutton University of Nottingham, United Kingdom

Jenny Quillien Embodied Making Institute, United States

Annette Vee University of Pittsburgh, United States

Ten essays were submitted and three accepted:

Interdisciplinary Programming Language Design, Michael Coblenz, Jonathan Aldrich, Brad A. Myers, and Joshua Sunshine-Carnegie Mellon University, USA; the essay was published in the Onward! proceedings, the extended abstract in this journal [I].

We Should Stop Claiming Generality in Our Domain-Specific Language Papers, Daco C. Harkes-Delft University of Technology, Netherlands; the essay was published in this journal, the extended abstract in the Onward! proceedings [3].

Fatal Abstraction, Friedrich Steimann-Fernuniversität in Hagen, Germany; the essay was published in the Onward! proceedings, the extended abstract in this journal [4]. 
The essays were presented on November 7 and 8, 2018, at Splash 2018 in Boston, Massachusetts.

Writing an essay is difficult for researchers and practitioners of programming. Essays provide a way for folks in the future to understand the climate of work being done today, and so can lead to new insights and new and perhaps unexpected directions.

\section{References}

[I] Michael Coblenz, Jonathan Aldrich, Joshua Sunshine, and Brad Myers. "Interdisciplinary Programming Language Design". In: Onward! 20I8: Proceedings of the 2018 ACM SIGPLAN International Symposium on New Ideas, New Paradigms, and Reflections on Programming and Software. Edited by Elisa Gonzalez Boix and Richard P. Gabriel. Onward! 2018. Boston, MA, USA: ACM, Nov. 2018, pages I33I46. ISBN: 978-I-4503-603I-9. DOI: 10.1145/3276954.3276965.

[2] Elisa Gonzalez Boix and Richard P. Gabriel, editors. Onward! 20I8: Proceedings of the 2018 ACM SIGPLAN International Symposium on New Ideas, New Paradigms, and Reflections on Programming and Software. Onward! 20I8. Boston, MA, USA: ACM, Nov. 20I8. ISBN: 978-I-4503-603I-9.

[3] Daco C. Harkes. "We Should Stop Claiming Generality in Our Domain-specific Language Papers (Extended Abstract)". In: Onward! 20I8: Proceedings of the $20 I 8$ ACM SIGPLAN International Symposium on New Ideas, New Paradigms, and Reflections on Programming and Software. Edited by Elisa Gonzalez Boix and Richard P. Gabriel. Onward! 20I8. Boston, MA, USA: ACM, Nov. 2018, pages I3II32. ISBN: 978-I-45O3-603I-9. DOI: 10.1145/3276954.3276967.

[4] Fredrich Steimann. "Fatal Abstraction". In: Onward! 20I8: Proceedings of the 2018 ACM SIGPLAN International Symposium on New Ideas, New Paradigms, and Reflections on Programming and Software. Edited by Elisa Gonzalez Boix and Richard P. Gabriel. Onward! 2018. Boston, MA, USA: ACM, Nov. 2018, pages I25I3O. ISBN: 978-I-4503-603I-9. DOI: 10.1145/3276954.3276966.

[5] Virginia Woolf. "Introduction". In: Life as We Have Known It. Edited by Cooperative Women's Guild. I93I. 
Introduction to the Special Issue of Onward! Essays 2018

About the author

Richard P. Gabriel is a computer scientist, poet, and writer, as well as a Visiting Researcher at the Hasso Plattner Institute. Contact him at rpg@dreamsongs.com. 